\title{
The Effects of Using Waste Engine Oil Bottom on Physical, Rheological Properties and Composite Modification Mechanism of SBS-Modified Asphalt
}

\author{
Yanbo Wang ${ }^{\mathbb{D}}$, Ailian Liu, Weixiang Ding, Fangping Rao, Jun Yuan, Zhihua Zhang, \\ Zhen $\mathrm{Xu}$, and Chuanzhou Dong
}

The Third Construction Engineering Co. Ltd. of China Construction Third Engineering Bureau, No. 2 Guannanyuan Road Hongshan District, Wuhan 430000, Hubei, China

Correspondence should be addressed to Yanbo Wang; pissaa@163.com

Received 20 August 2021; Accepted 22 December 2021; Published 7 January 2022

Academic Editor: Ramadhansyah Putra Jaya

Copyright ( $) 2022$ Yanbo Wang et al. This is an open access article distributed under the Creative Commons Attribution License, which permits unrestricted use, distribution, and reproduction in any medium, provided the original work is properly cited.

\begin{abstract}
This research explores the effects of using waste engine oil bottom on physical, rheological properties and composite modification mechanism of SBS-modified asphalt. The SBS asphalt binder was modified by WEOB with different concentrations $(2,4$, and 6 wt $\%)$. The GC-MS and FTIR spectrometry were conducted to evaluate the chemical compositions of WEOB-and WEOB-modified asphalt. RV, DSR, and BBR were tested to evaluate high- and low-temperature pavement performance. Fluorescence microscope (FM) test, bar thin layer chromatograph (BTLC) test, and AFM test were performed to evaluate the micromorphologies and modification mechanism. The test results showed that a new characteristic peak appeared in the infrared spectrum of the WEOBmodified SBS asphalt, indicating a chemical reaction in the modification process. Incorporation of WEOB improves both the hightemperature and low-temperature properties of the SBS asphalt binder. It was confirmed that with the increase of WEOB concentration, the content of colloid gradually increases, which promotes the swelling and compaction of SBS polymer network structure. Furthermore, WEOB promotes the polarity of SBS and forms graft product MAH-g-SBS with asphalt, thus inhibiting the thermal movement of asphalt molecules. On the contrary, light components have a good correlation with the surface roughness of modified asphalt; the results show that the modified asphalt has good rutting resistance.
\end{abstract}

\section{Introduction}

The large-scale construction of highway pavement is accompanied by a large consumption of asphalt, which is a nonrenewable material [1]. Therefore, modifying or regenerating asphalt to improve the quality of binder or reducing the consumption of new asphalt is an important means to save fossil fuel. Through the simple processing of waste oil materials, it can become an effective additive to modify asphalt. On the basis of improving the property of asphalt, it can also play a significant effect in environmental protection [2-4].

With the development of transportation industry and the continuous growth of car ownership, the production of waste engine oil (WEO) after vehicle maintenance is also ever-growing. WEO is classified as a hazardous waste because it poses a certain threat to the environment and human production and life [5]. The WEO is usually treated by combustion, which inevitably leads to soil and air pollution to a certain extent [6]. At present, WEO is generally recycled by ecological methods such as sedimentation and distillation, and the residue after process becomes waste engine oil bottom (WEOB) $[1,4,7]$. This method can maximize the use of resources and become the mainstream WEO disposal method.

A new survey shows that America can generate millions of gallons of WEOB annually [6]. The engine oil and asphalt belong to different products in the process of petroleum refining and have homology, which has been confirmed in previous studies [8]. In the process of production and use, 
the engine oil will inevitably change after passing through an environment of high temperature and high pressure $[9,10]$. In addition, certain physical and chemical changes will also occur in the process of refining and purifying waste engine oil. Therefore, the research on the properties of WEOB and asphalt blend has been a hot topic. Hesp's research team has been carrying out research on the properties after mixing between WEOB and asphalt in the recent 10 years [11].

The research team detected the existence of WEOB in asphalt by microscopic methods and verified the hypothesis that the early failure of asphalt pavement is related to the existence of WEOB [12]. After that, some researcher studied the influence of WEOB from different sources on the property of asphalt binder and found that WEOB had a negative impact on the high- and low-temperature performance of asphalt $[13,14]$.

However, different researchers hold diametrically opposite views on the promotion effect of $\mathrm{WEOB}$ on the property of asphalt binder [4, 14-16]. For instance, Qurashi et al. [7] evaluated the properties of WEOB-modified bitumens and found that WEOB increases the grade span and reduces the cracking performance of bitumen. Some research reported that the asphalt added with WEOB has good stress relaxation ability under short-term aging conditions [15]. Moreover, as it contains light components, WEO can act as a rejuvenator to recover some properties of asphalt $[7,17]$.

However, little research results have been reported at this point concerning the influence of the fusion of WEOB and SBS polymers on the properties of modified asphalt. In fact, modified asphalt is more used as binder in road construction. Therefore, it is particularly important to carry out the research between SBS-modified asphalt and WEOB modifier.

In this paper, four kinds of WEOB concentration were selected to prepare four types of WEOB-modified SBS asphalt. The effects of organic reagents on the properties of modified asphalt were studied in the microstructure level. Thus, the objectives of this study will be as follows:

(1) To evaluate the synergistic effect of WEOB and SBS polymer on physical and rheological properties of asphalt binder and then recommend an optimum WEOB content

(2) To explore the modification mechanisms of WEOB/ SBS-modified asphalt

For convenience, the flowchart of this work is summarized and illustrated in Figure 1.

\section{Materials and Methods}

2.1. Materials. Tests were performed on representative samples of SBS-modified binder (the dosage of SBS was $4.3 \mathrm{wt} \%)$, and its properties are listed in Table 1. WEOB used was purchased from local Motor Madness. It was a byproduct of refining waste engine oil through vacuum distillation, centrifugal separation, and other processes.
Figure 2 shows the processing technology of WEOB. Elemental compositions of WEOB are listed in Table 2.

2.2. Preparation of WEOB-Modified Binders. As engine oil and bitumen are products of crude oil refining, they are homologous, which makes direct mixing possible [18]. WEOB-modified SBS asphalt was prepared by heating blending method, the details of which are presented in Figure 3. The WEOB contents were selected based on the conclusions of previous research, as shown in Table 3. Four WEOB contents were designed as $0 \%, 2 \%, 4 \%$, and $6 \%$ of asphalt binder mass, respectively.

2.3. Experimental Methods. The Brookfield viscosity test was introduced to evaluate the viscosity of different kinds of asphalt binders, which was done at test temperature ranges from $110^{\circ} \mathrm{C}$ to $180^{\circ} \mathrm{C}$ at intervals of $10^{\circ}$ according to the AASHTO method.

The multiple stress creep recovery (MSCR) was conducted at repeat loading of $0.1 \mathrm{kPa}$ and $3.2 \mathrm{kPa}$ to evaluate the deformation resistance, which was characterized by the parameter of the average recovery rate $(R)$ and unrecoverable flexibility (Jnr).

The bending beam rheometer (BBR) was obtained to characterize the cracking resistance of WEOB-modified asphalt. Tests were performed at $-12^{\circ} \mathrm{C}$ and $-18^{\circ} \mathrm{C}$.

The gas chromatograph (GC-MS) was conducted to evaluate the chemical component of WEOB. The potential chemical reaction of WEOB- and SBS-modified asphalt was obtained by FTIR (NICOLET 6700 TM).

In view of the different fluorescence effects of asphalt and SBS polymer, the swelling property of the WEOB-modified asphalt were evaluated by FM (MIKON, USA) images.

The AFM equipment (Bruker Corporation, Innova, USA) was proposed to observe the micromorphology characteristics of the binders. The test method adopts tapping mode and the resonance frequency of $260 \mathrm{KHz}$.

The content of four components (asphaltene, resin, aromatic hydrocarbon, and saturated hydrocarbons) of asphalt will change during the modification process. Therefore, the layered adsorption of different components can be quantitatively analyzed by bar thin layer chromatograph (BTLC) equipment, which is shown in Figure 4.

\section{Results and Discussion}

3.1. Chemical Components of WEOB. Figure 5 shows the GCMS chromatogram of WEOB, from which we can see the peaks formed by different compounds. The name and molecular structure of the compound can be found by analyzing the corresponding peak positions. The results are shown in Table 4. It can be seen that WEOB is mainly composed of cycloalkanes, linear alkanes, various anhydrides, and their derivatives. The molar mass of each compound is small, belonging to olefin oil and aromatic solvents, while anhydride is mainly the anhydride product formed by synthetic engine oil compound through high-temperature and high-pressure engine degreasing and other reactions. 


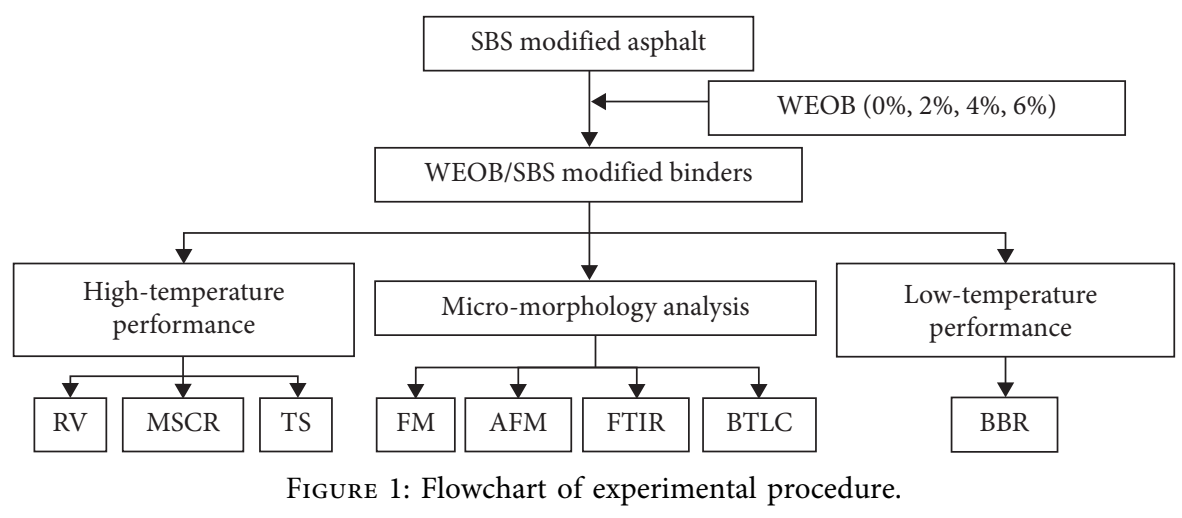

TABle 1: Properties of SBS-modified binder.

\begin{tabular}{lcc}
\hline Test properties & Unit & Test result \\
\hline Penetration $\left(25^{\circ} \mathrm{C}, 100 \mathrm{~g}, 5 \mathrm{~s}\right)$ & $0.1 \mathrm{~mm}$ & 50.7 \\
Ductility $\left(5^{\circ} \mathrm{C}, 5 \mathrm{~cm} / \mathrm{min}\right)$ & $\mathrm{cm}$ & 40.5 \\
Softening point $(\mathrm{TR} \& \mathrm{~B})$ & ${ }^{\circ} \mathrm{C}$ & 71.6 \\
\hline
\end{tabular}

3.2. Viscosity. Figure 6 shows the influence trend of WEOB on the viscosity of SBS-modified asphalt. It can be seen from the figure that the rotational viscosity of modified asphalt has a significant correlation with the test temperature and WEOB content. Specifically, the increase of temperature and the decrease of WEOB content will weaken the viscosity of modified asphalt. The increase of ambient temperature weakens the thermal movement limit of asphalt molecules, while the addition of WEOB improves the expansion of SBS polymer network structure, makes the three-dimensional structure more uniform and denser, and limits the flow capacity of asphalt molecules to a certain extent. In order to facilitate construction, the specification has strict requirements on rotational viscosity, that is, at $135^{\circ} \mathrm{C}$, the rotational viscosity shall not exceed 3.0 Pa.s. It can be seen from the figure that the limit rotational viscosity value of WEOBmodified asphalt does not exceed the threshold under this temperature condition. Therefore, under certain dosage conditions, the addition of WEOB can meet the construction requirements.

3.3. High-Temperature Property. The cumulative strain results of modified asphalt with different WEOB content under $64^{\circ} \mathrm{C}$ and $3.2 \mathrm{kPa}$ stress are shown in Figure $7 . \mathrm{Ob}$ viously, compared with SBS-modified asphalt without WEOB, the cumulative strain of asphalt decreases sharply after adding, and the downward trend is more obvious with the increase of content, which shows that WEOB has a positive effect on improving the high-temperature deformation resistance of SBS-modified asphalt. The result is the same as the conclusion of rotational viscosity.

To quantitatively evaluate the influence of WEOB on the cumulative strain of modified asphalt at high temperature, the $R$ and Jnr are calculated based on the data (Figure 7) and equations (1) and (2), and the results are shown in Figure 8. Regardless of the stress level and test temperature, the concentration dependency of $R$ and $J$ are remarkable in that the $R$ increase and $J$ reduces as WEOB content rises, which indicates that the existence of WEOB improves the hightemperature recovery ability of WEOB-modified asphalt more, and the larger WEOB content corresponds to the better high-temperature property. This result can be explained by the fact that the light component contained in WEOB reacts with SBS polymer to form a network structure, and the more the content is, the denser the structure is, and the stronger the high-temperature deformation resistance is.

To distinctly compare the high-temperature creep and recovery behaviors of SBS-modified binders with various WEOB contents, the data at the fifth loading stage from Figure 7 are extracted and plotted in Figure 9. The creep behavior (Figure 9(a)) is first discussed. It is obvious that a decrease of accumulated strain is observed with the introduction of WEOB into asphalt, meaning that the existence of WEOB causes a reduction in the creep behavior of the SBSmodified binder. Figure 9(a) also demonstrates that among these WEOB/SBS-modified binders, the binder containing $6 \mathrm{wt} \%$ of WEOB exhibits larger creep behavior than the counterparts with $2 \mathrm{wt} \%$ and $4 \mathrm{wt} \%$ WEOB which have little difference in creep behavior. Furthermore, the strain of all binder samples increases exponentially with time. Based on this curve feature and the previous work by You et al. [21], Burgers model (see Equations (1) and (2)) is applied to fit the creep behavior of these binders, and the fitting results are shown in Table 5 . It can be seen that the correlation coefficients exceed 0.999 , suggesting the excellent applicability of Burgers model in fitting the creep behavior of SBS/WEOBmodified binders. Importantly, the elastic and viscous deformations are further divided into instantaneous and delayed parts, respectively, which provides the possibility to better understand the deformation process of the binder.

To facilitate evaluation of the WEOB content influence on the high-temperature recovery behavior of the binder, the strain in the recovery stage is normalized and then plotted in Figure 9(b). The normalized value is referred to as residual deformation [22]. As it can be seen, the residual 


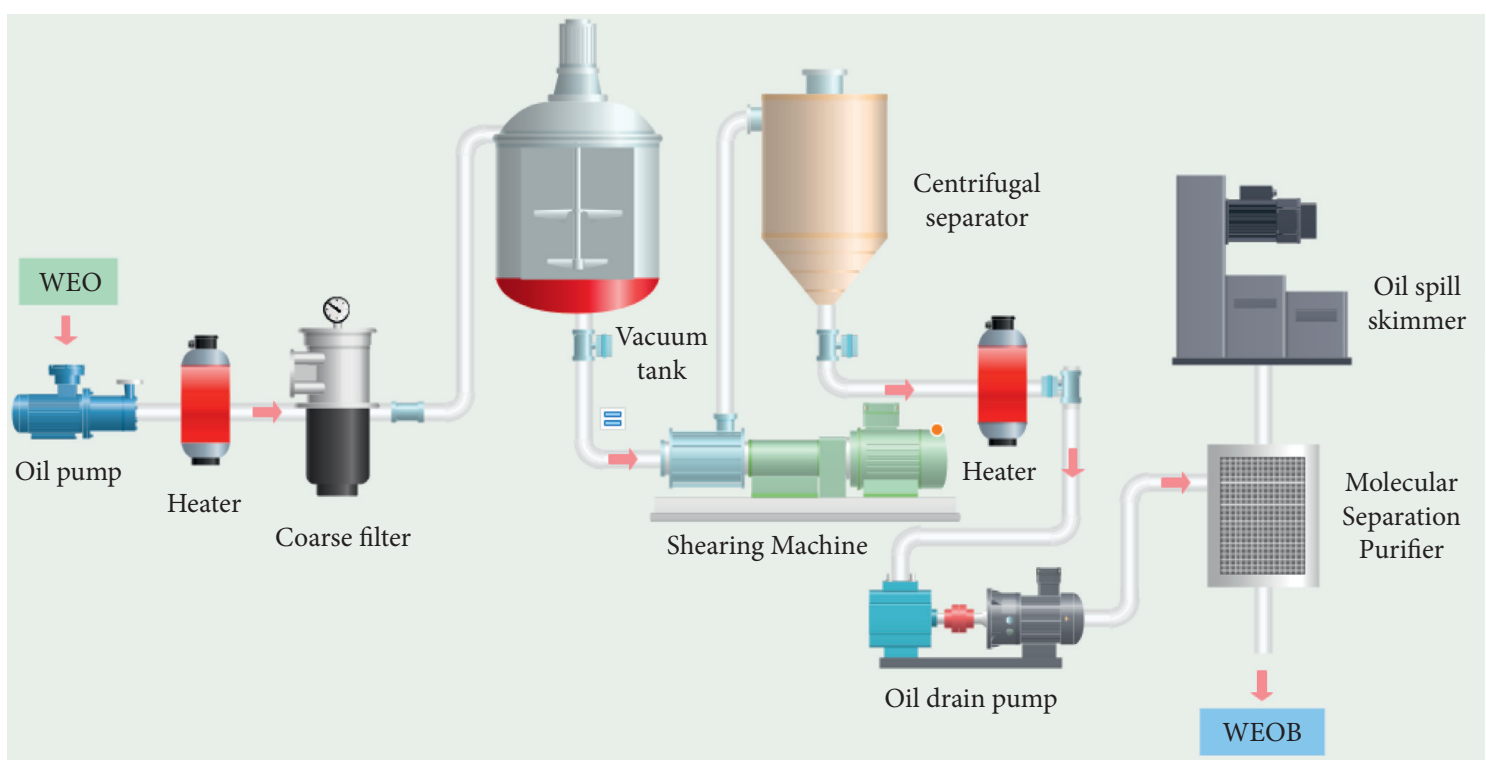

FIgURe 2: Processing technology of WEOB.

TABLE 2: Elemental composition and technical properties of WEOB.

\begin{tabular}{|c|c|c|c|c|c|c|c|c|}
\hline Phosphorus (\%) & Sulfur (\%) & Calcium (\%) & Iron (\%) & Copper (\%) & Zinc (\%) & Molybdenum (\%) & Dynamic viscosity $(\mathrm{Pa} \cdot \mathrm{s})$ & $\mathrm{pH}$ \\
\hline 1.39 & 1.68 & 0.91 & 0.15 & 0.4 & 0.59 & 0.04 & $18.2 @ 60^{\circ} \mathrm{C}$ & 3.4 \\
\hline
\end{tabular}

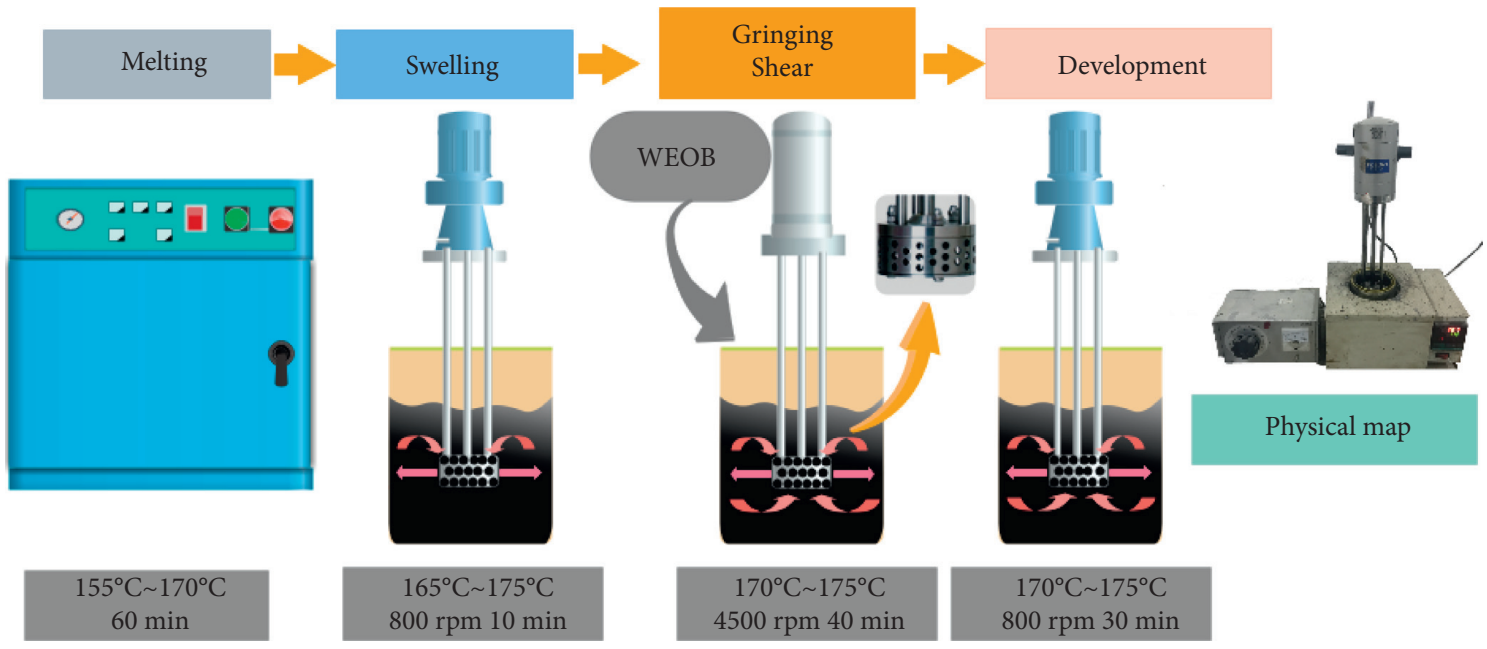

Figure 3: Preparation process of WEOB/SBS-modified binder.

TABLE 3: WEOB or WEO content in existing studies and practices.

\begin{tabular}{lcc}
\hline Content & Asphalt type & Literature \\
\hline $0 \%, 2 \%, 4 \%, 6 \%, 8 \%$ & VG-30 & Qurashi and Swamy [7] \\
$6 \%, 8 \%$ & Polymer-modified binders & Paliukaiteet al. [19] \\
$0 \%, 4 \%, 8 \%$ & 60/80 pen-grade base asphalt and & Liu et al. [20] \\
\hline
\end{tabular}

deformations from large to small are $0.64,0.60,0.52$, and 0.29 corresponding to SBS-modified binders with the WEOB content of $2 \%, 4 \%, 0 \%$, and $6 \%$, respectively. Considering the residual deformation is a consequence of viscous flow, the creep deformation of the binder with $6 \mathrm{wt} \%$ of WEOB is primarily caused by elasticity. However, other binders that have the residual deformation larger than 0.5 show more viscous deformation than elastic deformation. In view of the 

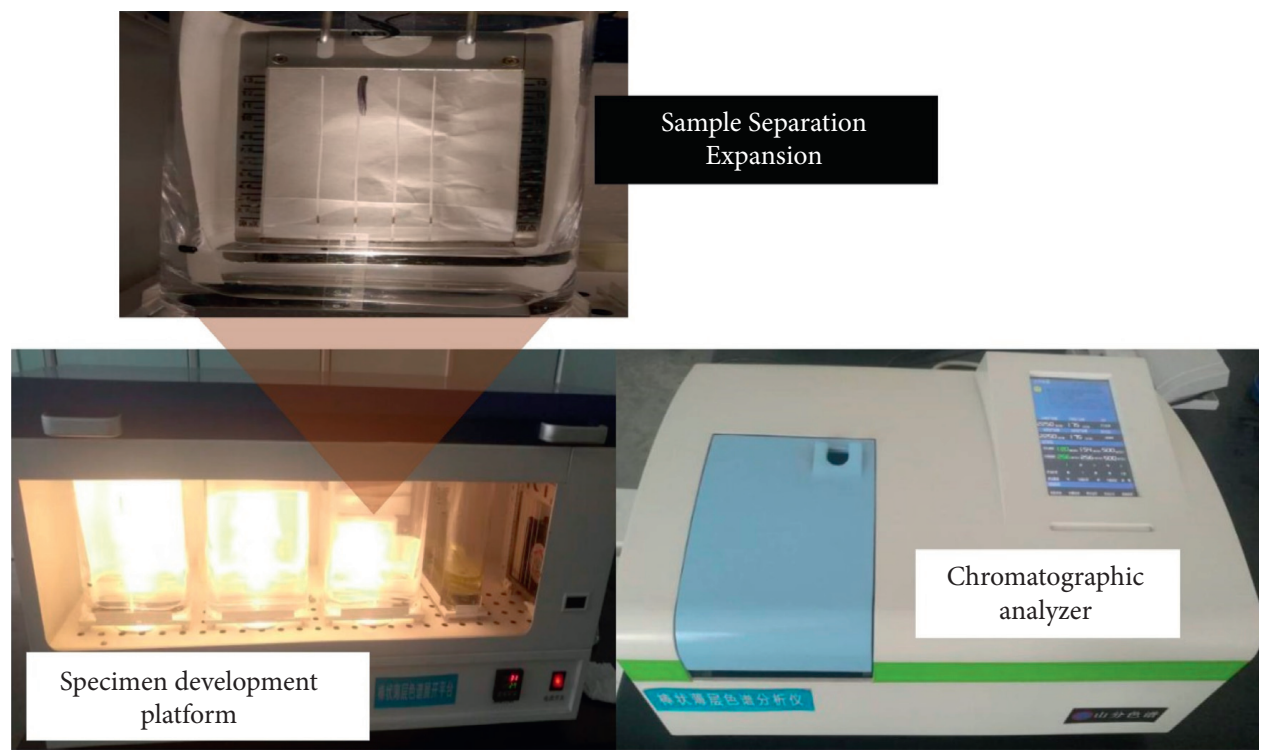

FIGURE 4: Setup for bar thin layer chromatography analyzer.

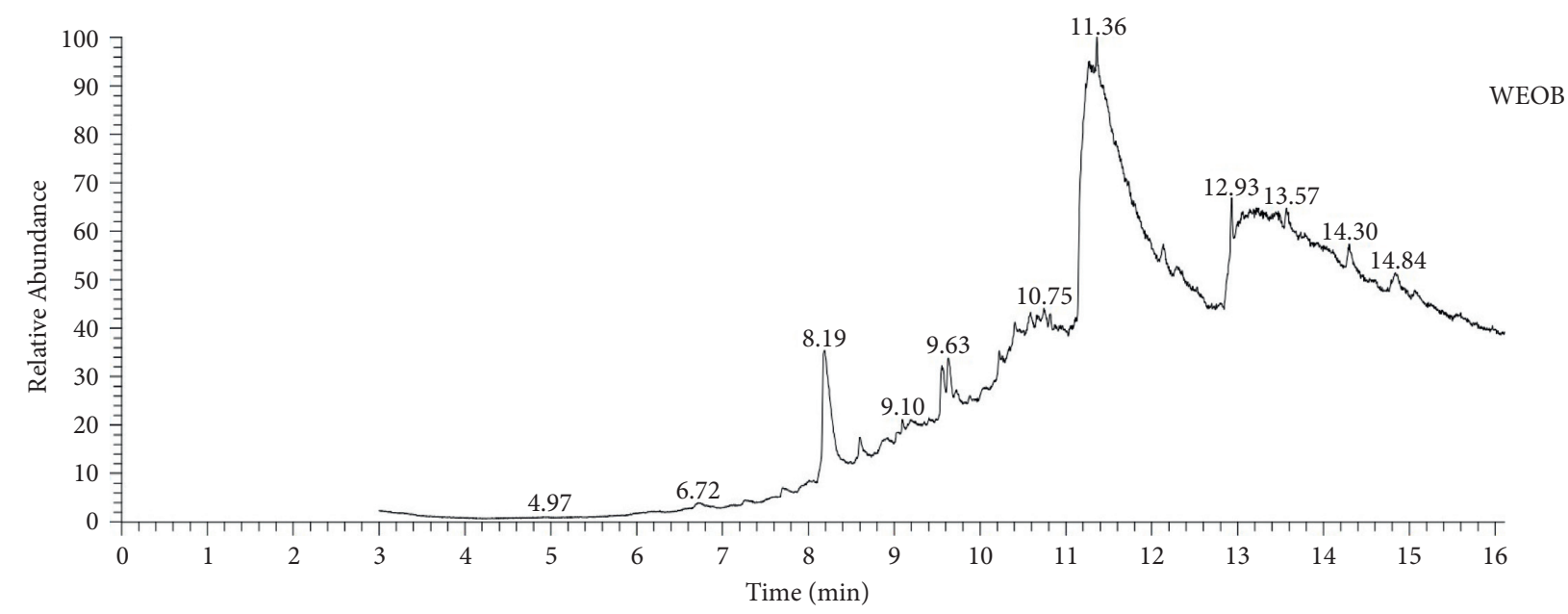

Figure 5: GC-MS chromatogram of WEOB.

similar curve feature in Figure 9(a), the curves in Figure 9(b) can be fitted by Burgers model as well. According to the result in Table 6, it is obtained that Burgers model is capable of perfectly fitting the recovery behavior of SBS/WEOBmodified binders owing to the $R^{2}$ exceeding 0.99 .

$$
\begin{aligned}
& \varepsilon(t)=\frac{\sigma_{0}}{E_{1}}+\frac{\sigma_{0}}{\eta_{1}}+\frac{\sigma_{0}}{E_{2}}\left(1-e^{-E_{2} t / \eta_{2}}\right) . \\
& \varepsilon(t)=\frac{E_{1} \eta_{1} E_{2}}{\eta_{1} E_{2}+E_{1} E_{2} t+E_{1} \eta_{1}\left(1-e^{-E_{2} t / \eta_{2}}\right)},
\end{aligned}
$$

where $\sigma_{0}$ is the initial stress $(\mathrm{Pa})$, Young's modulus $(\mathrm{Pa})$ is recorded as $E$, and $\eta$ is the viscosity (Pa.s).

3.4. Low-Temperature Property. The creep stiffness modulus $(S)$ and creep slope $(m)$ of modified asphalt with various WEOB content under different low-temperature environments are shown in Figure 10. Generally, a larger $S$ represents more tensile stress, and a larger $m$ value means more stress relaxation. Apparently, the small $S$ value and large $m$ value at low temperature are preferred for asphalt binder. It can be seen from Figure 10 that at the temperatures of $-12^{\circ} \mathrm{C}$ and $-18^{\circ} \mathrm{C}$, with the increase of WEOB content, $S$ value decreases and $m$ value increases, which significantly improves the low-temperature deformation resistance of surface asphalt with the addition of WEOB. The possible reason for this phenomenon is that the addition of light components, which increases the maltenes concentration of asphalt. Moreover, the SBS polymer expands effectively in the surplus light component environment and forms a network structure with resistance to low-temperature cracking and deformation. In addition, under the action of $\mathrm{MAH}, \mathrm{WEOB}$ and SBS form graft products, which play a positive role in improving the relaxation and deformation ability. 
TABLE 4: The chemical composition of WEOB.

\begin{tabular}{|c|c|c|c|c|c|}
\hline $\begin{array}{l}\text { Retention } \\
\text { time (min) }\end{array}$ & Formula & Structure & $\begin{array}{l}\text { Retention } \\
\text { time (min) }\end{array}$ & Formula & Structure \\
\hline 6.72 & $\mathrm{C}_{4} \mathrm{H}_{2} \mathrm{O}_{3}$ & & 11.36 & $\mathrm{C}_{16} \mathrm{H}_{32} \mathrm{O}_{2}$ & \\
\hline 8.19 & $\mathrm{C}_{15} \mathrm{H}_{24} \mathrm{O}$ & & 12.93 & $\mathrm{C}_{17} \mathrm{H}_{32} \mathrm{O}_{2}$ & \\
\hline 9.10 & $\mathrm{C}_{16} \mathrm{H}_{26} \mathrm{O}_{3}$ & & 13.57 & $\mathrm{C}_{19} \mathrm{H}_{40}$ & \\
\hline 9.63 & $\mathrm{C}_{20} \mathrm{H}_{42}$ & & 14.30 & $\mathrm{C}_{28} \mathrm{H}_{48} \mathrm{O}$ & \\
\hline 10.75 & $\mathrm{C}_{15} \mathrm{H}_{24} \mathrm{O}_{2}$ & & 14.87 & $\mathrm{C}_{20} \mathrm{H}_{38} \mathrm{O}_{2}$ & \\
\hline
\end{tabular}

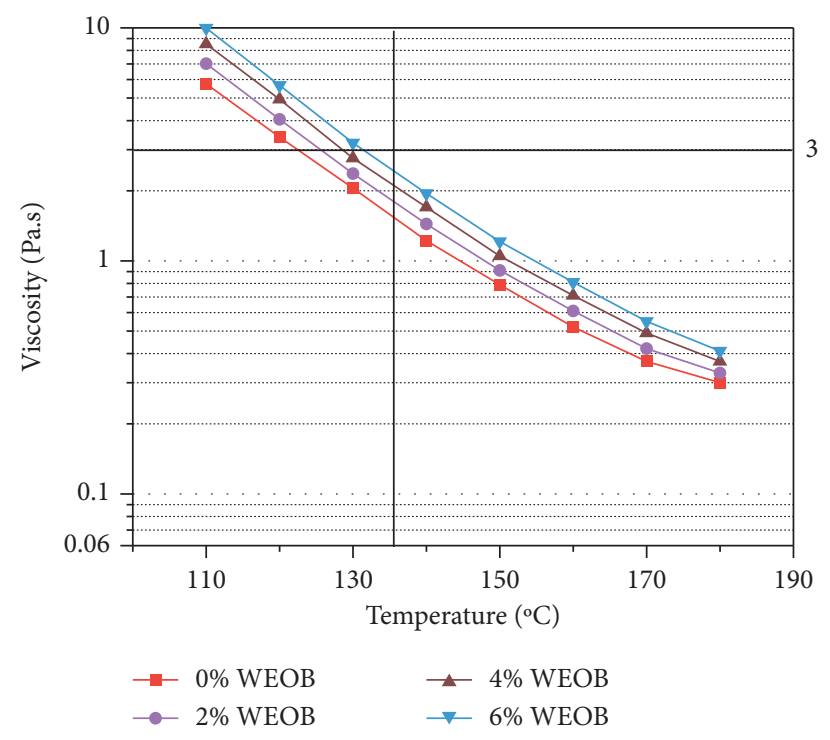

FIGURE 6: Viscosity results of the WEOB/SBS-modified binders.

\subsection{Mechanical Analysis}

3.5.1. SARA Fractions. SARA fraction contents play an important role in explaining the property changes of asphalt binder. Figure 11 records the quantitative analysis results of four components of asphalt. As WEOB contains a certain number of light components, with the increase of the WEOB contents, the number of aromatic hydrocarbons and saturated hydrocarbons in the four components gradually increases, which plays a good role in improving the lowtemperature property of asphalt. On the contrary, the content of asphaltene shows a downward trend because it is dissolved by the light components in WEOB. However, the resin content has increased to a certain extent. It is speculated that the possible reason is that a large number of aromatic hydrocarbons in WEOB are compatible with SBS and penetrate into the branch chain to produce substances 


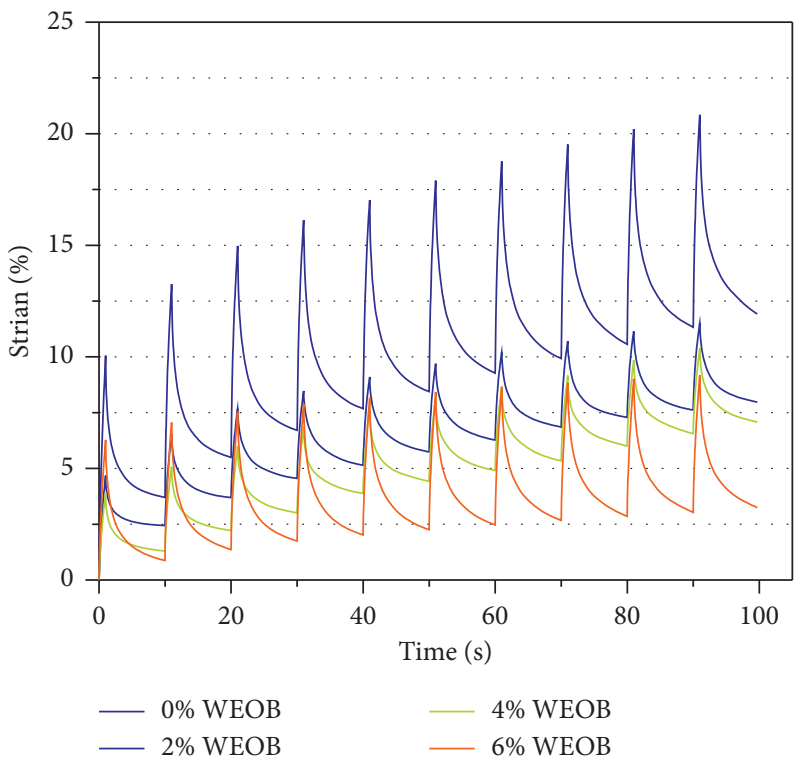

Figure 7: Strain response in MSCR test (10 cycles) for binders at $64^{\circ} \mathrm{C}$ and $3200 \mathrm{~Pa}$.
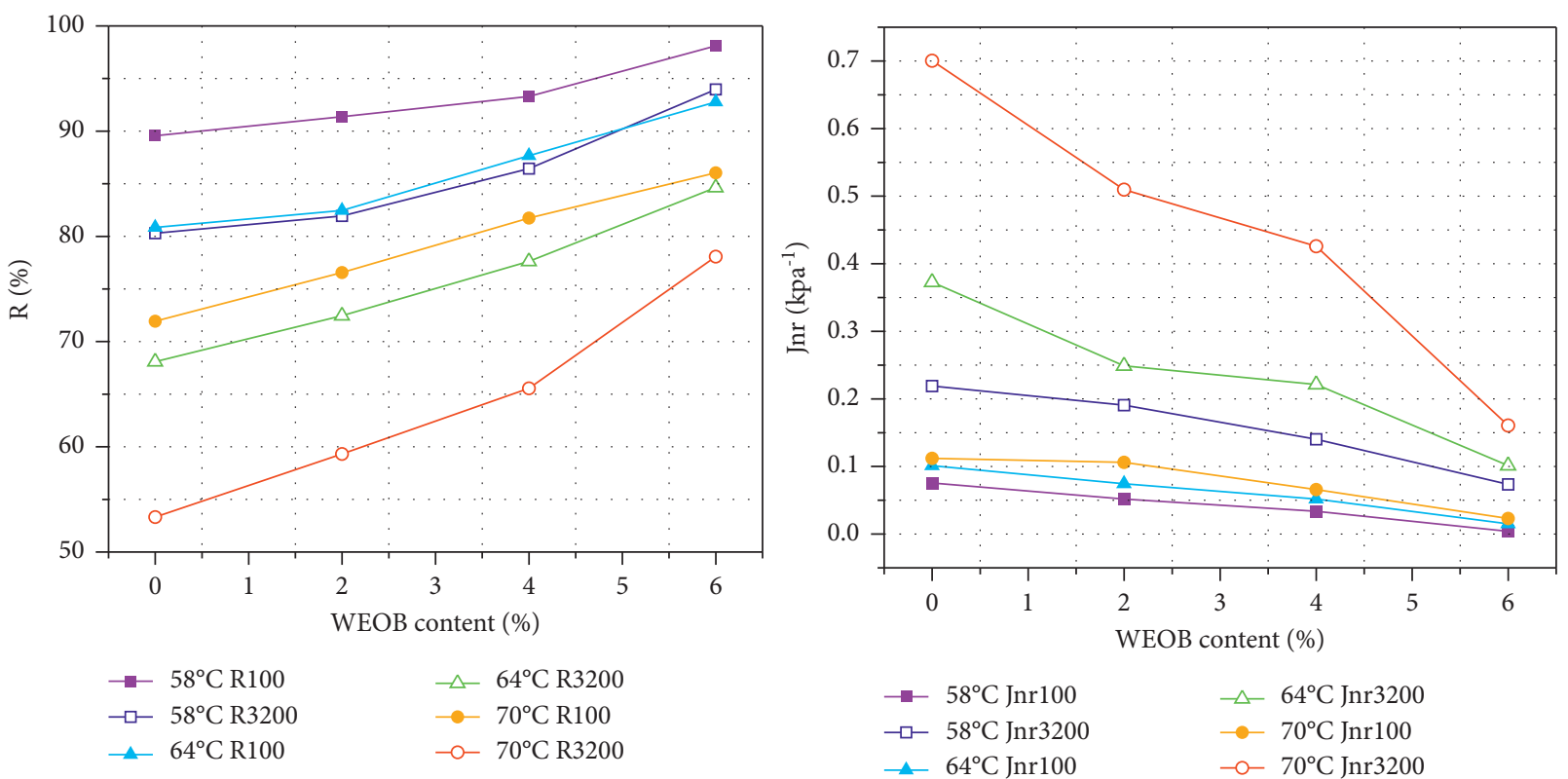

Figure 8: $R$ (a) and $J(b)$ for WEOB/SBS-modified binders at various temperatures.

similar to resins, which increases the stability of SBS network structure. This is also proved by the improvement of hightemperature performance of asphalt.

3.5.2. Fluorescence Microscopy. The fusion degree of different contents of WEOB- and SBS-modified asphalt can be seen from the fluorescence microscopic image in Figure 12. In Figure 12(a), it can be seen that in the modified asphalt without WEOB, SBS presents uniform monomer particle dispersion, and there is little fusion between SBS polymers. After adding WEOB, SBS polymer shows a network structure after expansion and fusion, and with the increase of content, the structure gradually develops from two-dimensional plane network structure to three-dimensional network structure, as shown in Figures 12(b)-12(d), and the thermal movement of asphalt molecules is limited to a certain extent. When the content of WEOB increased to 6\%, the expanded network structure was denser and uniform. In addition, the maleic anhydride in WEOB reacted with SBS. Under the dual action of swelling and grafting, the high-temperature performance of WEOB-modified asphalt was significantly improved $[23,24]$.

3.5.3. FTIR. The FTIR spectra of the SBS-modified asphalts with various WEOB contents are given in Figure 13. A peak at $724 \mathrm{~cm}^{-1}$ was awarded to the bending vibration of $-\mathrm{CH}_{2}$, while that at $1,713 \mathrm{~cm}^{-1}$ was credited to tensile vibration of 


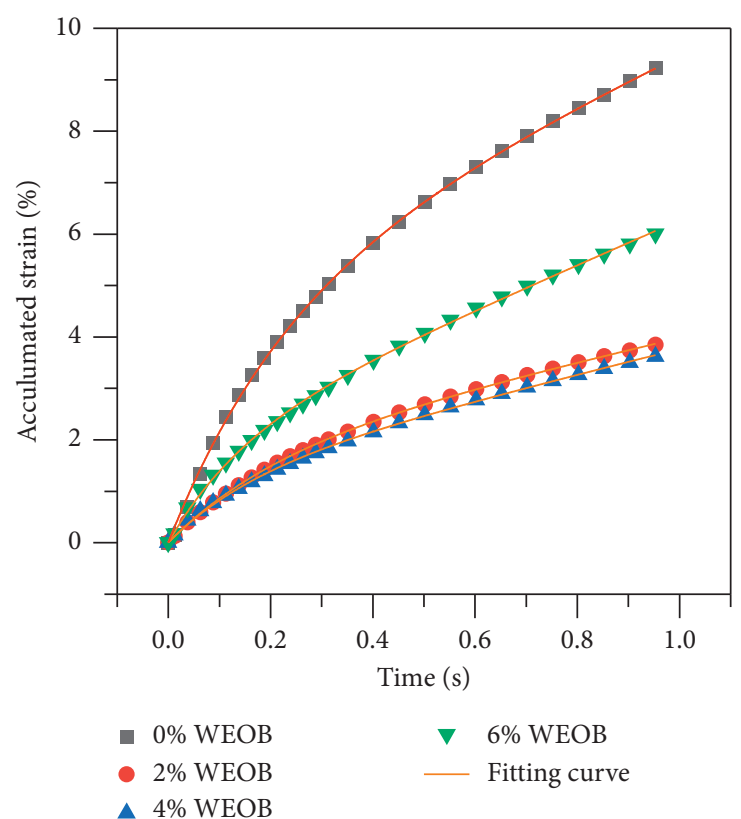

(a)

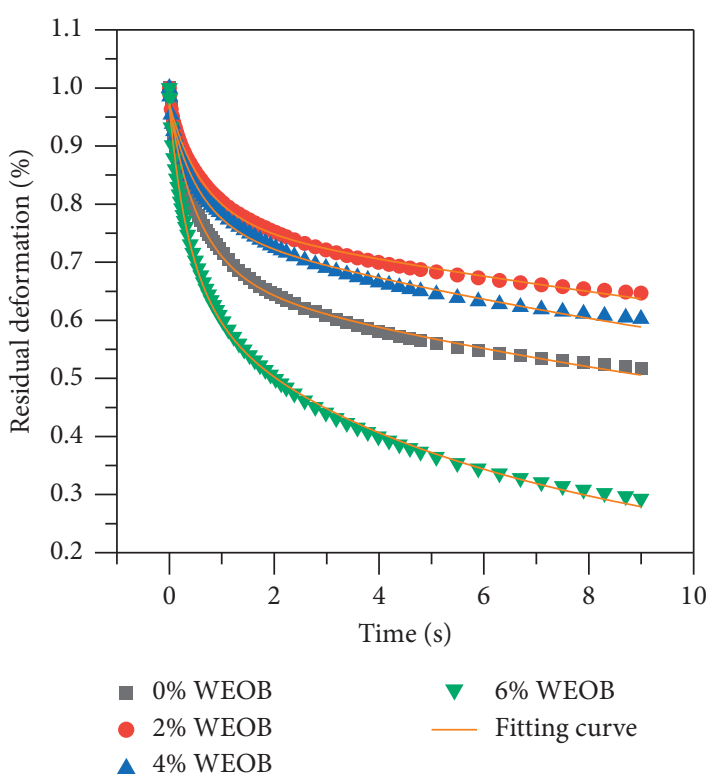

(b)

FIgURE 9: Comparison of measured and predicted values of SBS asphalt with different WEOB content in Burgers Model.

TABLE 5: Regression analysis of creep for SBS modifier asphalt with different WEOB content in Burgers model.

\begin{tabular}{lcc}
\hline \multirow{2}{*}{ Ratio } & \multicolumn{2}{c}{ Regression equation and parameters of Burgers model } \\
& \multicolumn{1}{c}{ Equation } & $R^{2}$ \\
\hline 0 & $\mathcal{E}(t)=\frac{\sigma_{0}}{500.16}+\frac{\sigma_{0}}{9347.2}+\frac{\sigma_{0}}{1126.08}\left(1-e^{-1126.08 t / 901.44}\right)$ & 0.9995 \\
2 & $\varepsilon(t)=\frac{\sigma_{0}}{285.664}+\frac{\sigma_{0}}{9760}+\frac{\sigma_{0}}{1077.76}\left(1-e^{-1077.76 t / 875.2}\right)$ & 0.9999 \\
4 & $\varepsilon(t)=\frac{\sigma_{0}}{345.28}+\frac{\sigma_{0}}{8377.6}+\frac{\sigma_{0}}{1264.32}\left(1-e^{-1264.32 t / 896.64}\right)$ & 0.9995 \\
6 & $\varepsilon(t)=\frac{\sigma_{0}}{1091.2}+\frac{\sigma_{0}}{5001.6}+\frac{\sigma_{0}}{2109.44}\left(1-e^{-2109.44 t / 1332.48}\right)$ & 0.9994 \\
\hline
\end{tabular}

TABLE 6: Regression analysis of relaxation for SBS modifier asphalt with different WEOB content in Burgers model.

\begin{tabular}{llc}
\hline Ratio & \multicolumn{2}{c}{$\begin{array}{c}\text { Regression and equation parameters } \\
\text { of Burgers model } \\
\text { Equation }\end{array}$} \\
\hline 0 & $\varepsilon(t)=\frac{5.6^{*} 10^{5}}{4.1+376 t+312\left(1-e^{-657.28 t / 154.976}\right)}$ \\
2 & $\varepsilon(t)=\frac{4.6^{*} 10^{5}}{3.2+320 t+241\left(1-e^{-1845.44 t / 418.88}\right)}$ & 0.9955 \\
4 & $\varepsilon(t)=\frac{1.8^{*} 10^{5}}{2.6+134 t+74.8\left(1-e^{-241.08 t}+476.16\right)}$ & 0.9957 \\
6 & $\varepsilon(t)=\frac{8.34^{*} 10^{4}}{1.23+111 t+51\left(1-e^{-1652.16 t / 260.48}\right)}$ & 0.9936 \\
\hline
\end{tabular}

$\mathrm{C}=\mathrm{O}$, indicating the presence of ketones or carboxylic acids in the asphalt. The two strong absorptions at $1,376 \mathrm{~cm}^{-1}$ and $1,456 \mathrm{~cm}^{-1}$ were the flexural vibration peak of saturated $\mathrm{C}-\mathrm{H}$ bond. The stretching peak of methyl $\mathrm{C}=\mathrm{C}$ bond appeared at $1,608 \mathrm{~cm}^{-1}$, suggesting the existence of olefins. This result is consistent with a previous study. At $1,780 \mathrm{~cm}^{-1}$, the symmetrical tensile vibration peak is $-\mathrm{OH}$, which is the characteristic peak of maleic anhydride $(\mathrm{MAH})$, proving the existence of SBS-g-MAH. The several peaks in the
$2852-2923 \mathrm{~cm}^{-1}$ wavenumber range are attributed to the stretching of the alkane $-\mathrm{CH}$ bond.

3.5.4. Atomic Force Microscope. A typical "bee-like" structure AFM image of asphalt is shown in Figure 14. Studies have shown that the volume and distribution of black-and-white "bee-like" structure are related to asphaltene in asphalt. It can be seen from the Figures 14(a)$14(d)$ that the size and shape of "bee-like" structure are various under different WEOB content, but they all show a state of uniform distribution. With the increase of WEOB content, the bee-like structure gradually becomes smaller, and the length decreases from $3.21 \mu \mathrm{m}$ to $1.27 \mu \mathrm{m}$. It is speculated that the reason is that more light components in WEOB dissolve parts of asphaltene, and the movement resistance between asphaltenes is reduced and the compatibility is improved, so that the bee-like structure is dispersed more evenly.

Quantitative microstructures can be identified with surface roughness using the Nanoscope Analysis 1.5 software. Theoretically, surface roughness can be used to evaluate the adhesion and self-healing performance of asphalt materials. The higher the surface roughness of the asphalt binders, the better the adhesion and self-healing properties of the asphalt binders. The statistical results for surface roughness of four asphalt types are presented in Table 7. It can be seen that the surface roughness of asphalt binder increases with the increasing contents of WEOB.

Figure 15 shows that the variation trend of lightweight components and surface roughness with WEOB content. It is obvious to see that the lightweight components and surface roughness of SBS-modified asphalt specimens are in 


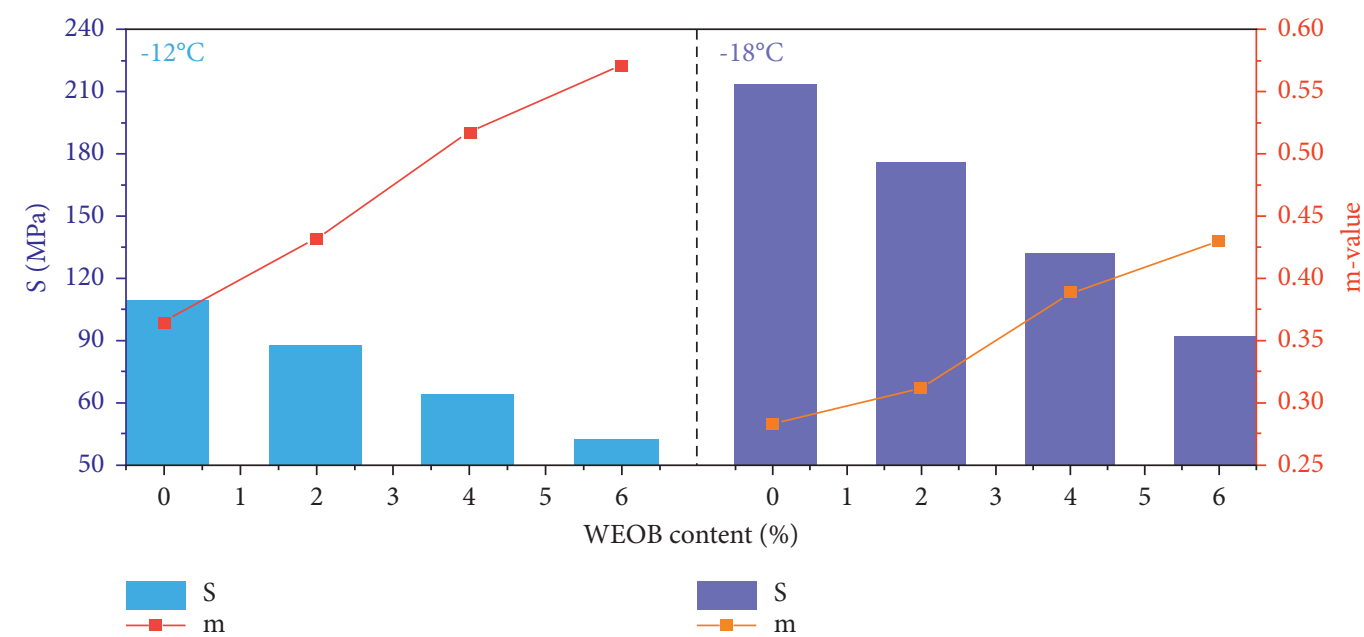

FIGURE 10: BBR test results of WEOB/SBS-modified binders at $-12^{\circ} \mathrm{C}$ and $-18^{\circ} \mathrm{C}$.

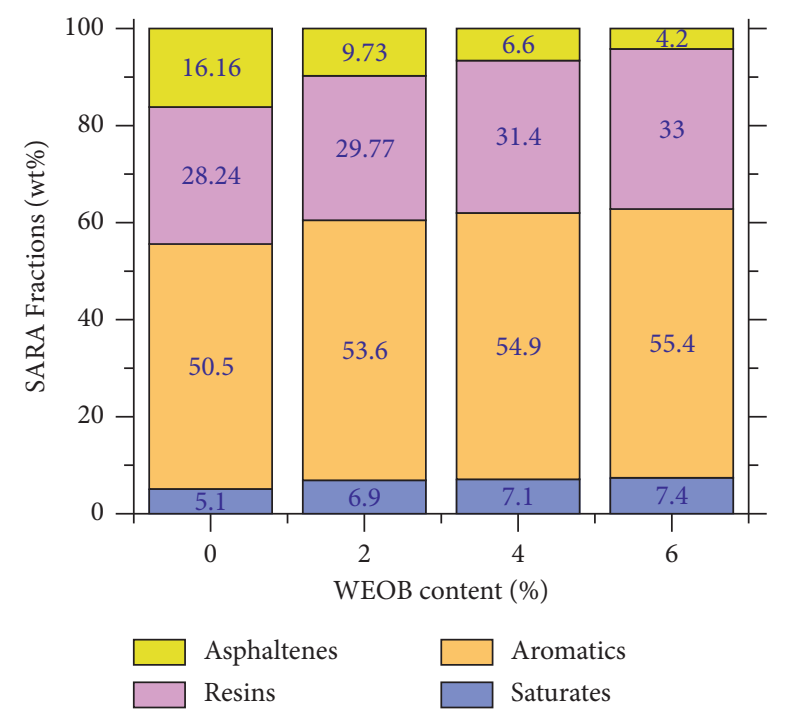

FIGURE 11: SARA fraction contents of WEOB/SBS-modified binders.
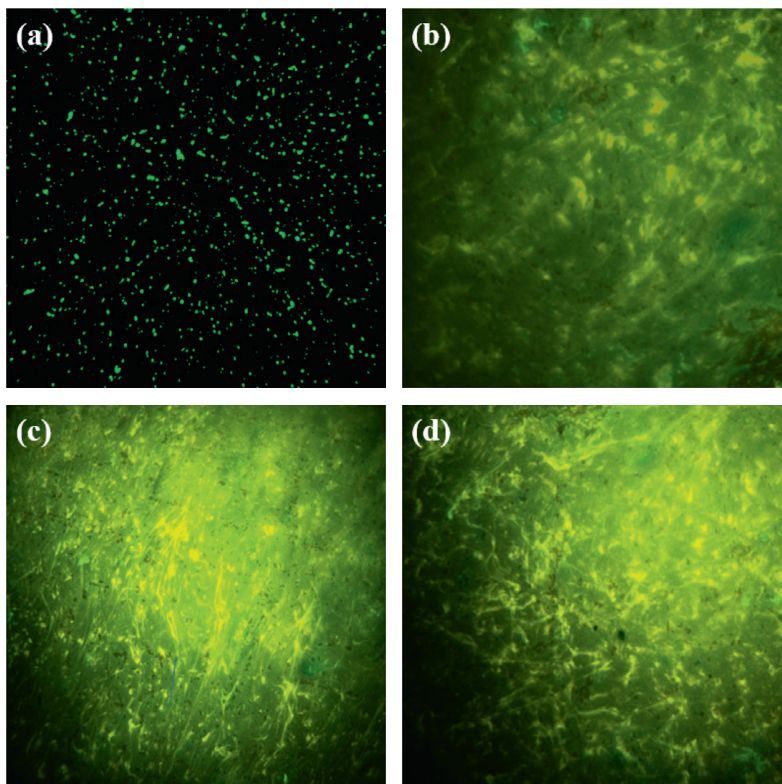

Figure 12: Fluorescence Microscopy for WEOB/SBS-modified binders with various WEOB content (a) $0 \%$, (b) $2 \%$, (c) $4 \%$, and (d) $6 \%$. 


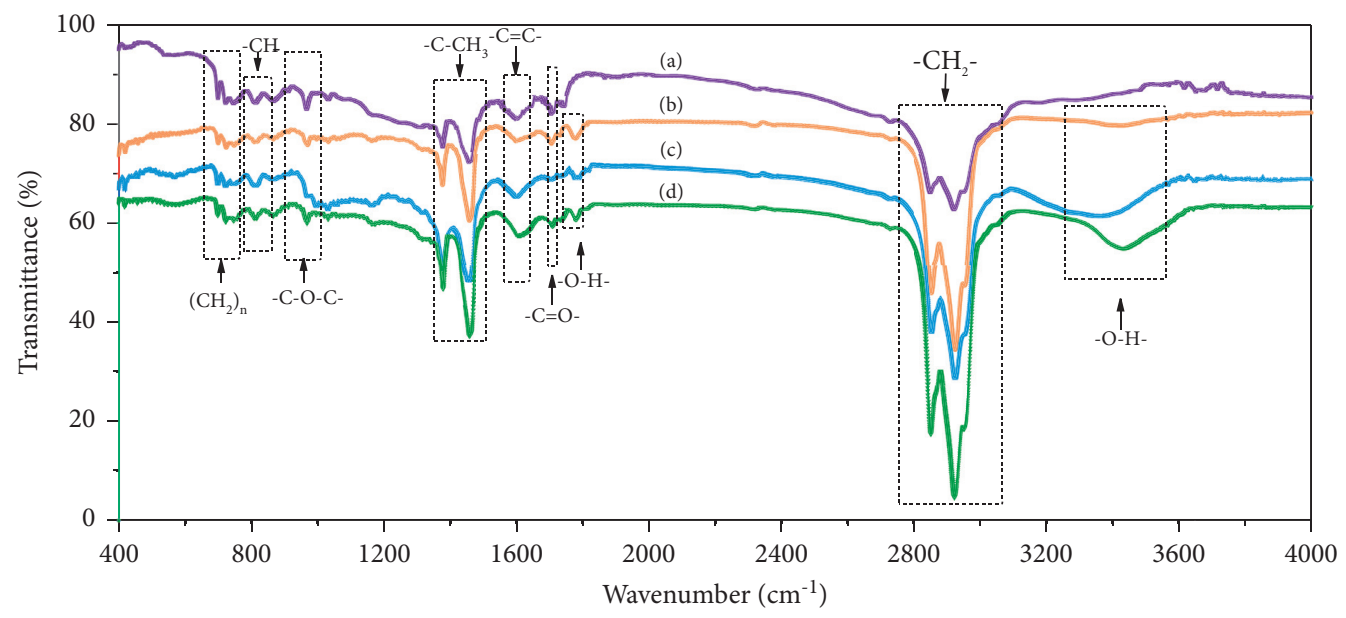
(a) $-0 \% \mathrm{WEOB}$
(c) — 4\% WEOB
(b) $-2 \%$ WEOB
(d) - $6 \%$ WEOB

FIGURE 13: FTIR of WEOB-modified asphalt.

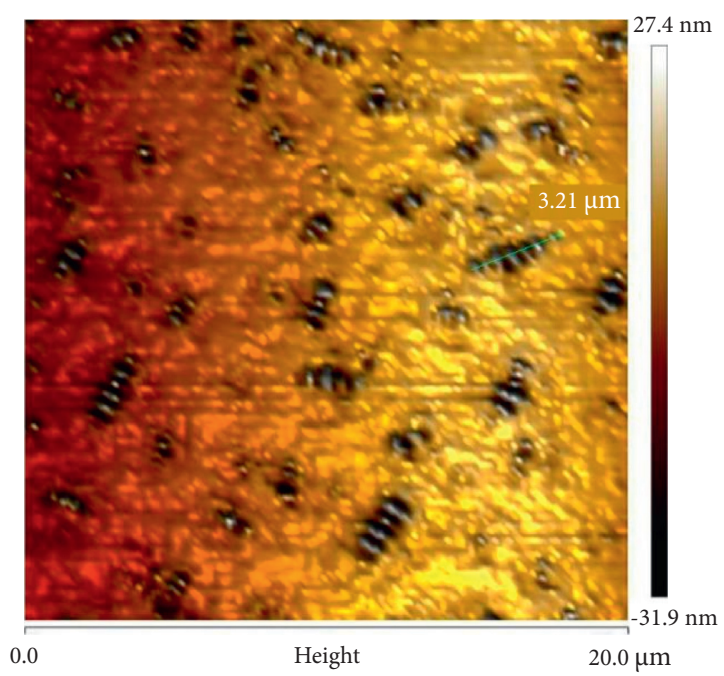

(a)

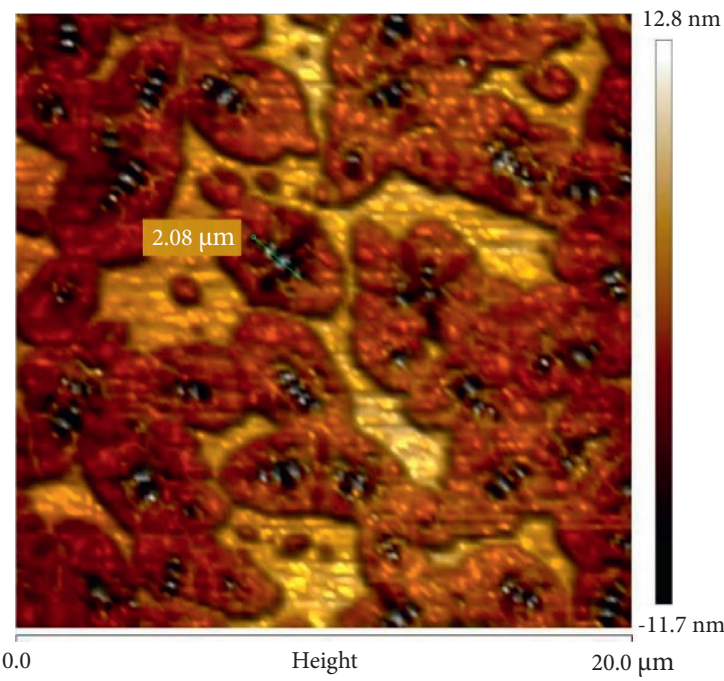

(c)

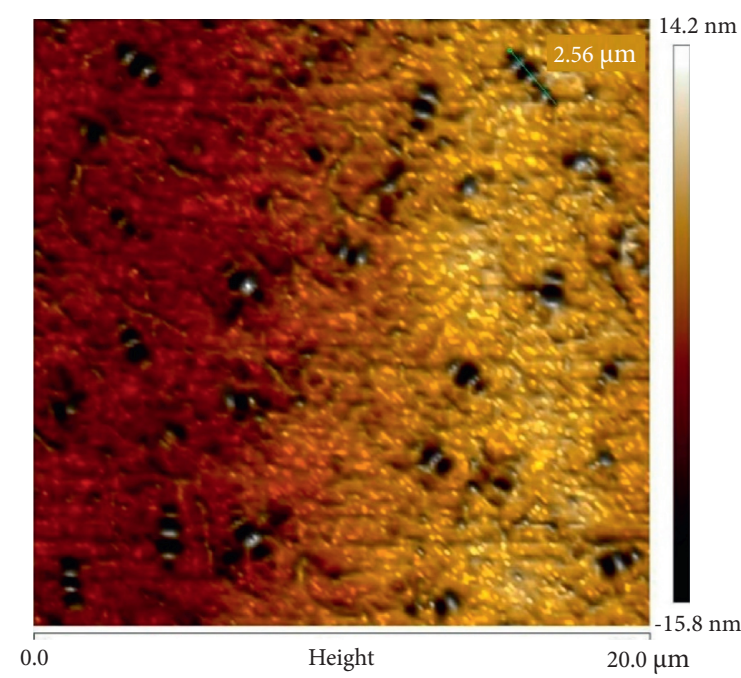

(b)

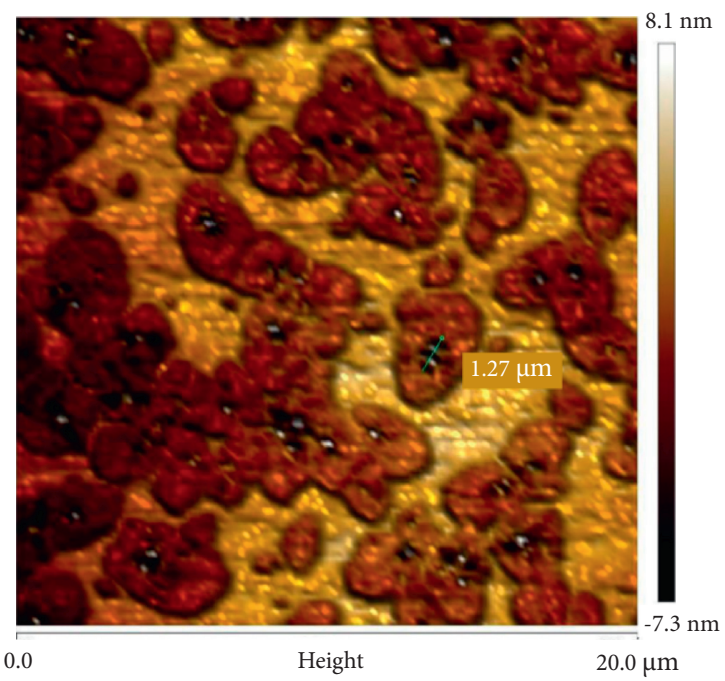

(d)

FIgURE 14: Phase images of WEOB-modified SBS asphalt, (a) $0 \%$, (b) $2 \%$, (c) $4 \%$, and (d) $6 \%$. 
TABLE 7: Statistical results of surface roughness.

\begin{tabular}{lcr}
\hline Asphalt type & Average surface roughness $\left(R_{a}\right)$ & RMS value of roughness $\left(R_{q}\right)$ \\
\hline $0 \%$ WEOB & 2.38 & 4.00 \\
$2 \%$ WEOB & 2.75 & 4.62 \\
$4 \%$ WEOB & 3.22 & 5.09 \\
$6 \%$ WEOB & 3.54 & 5.42 \\
\hline
\end{tabular}

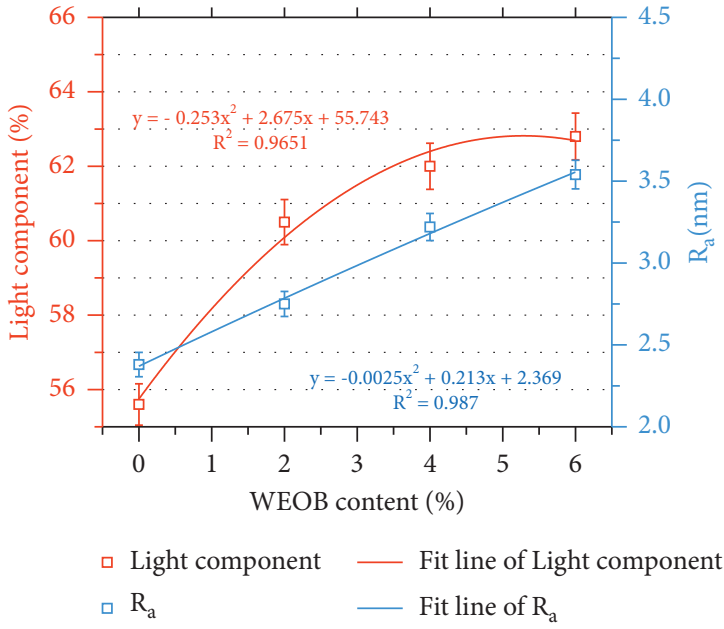

(a)

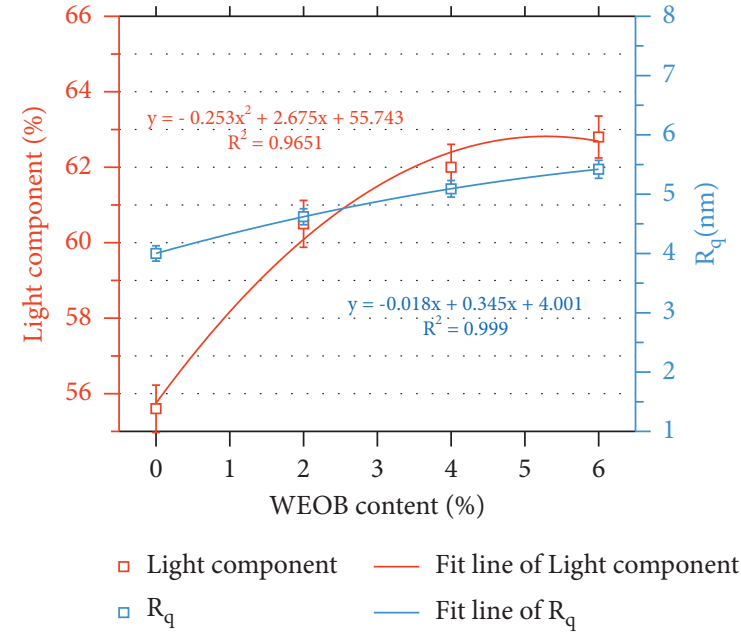

(b)

Figure 15: (a) $R_{a}$ and (b) $R_{q}$ of the specimens with different WEOB contents.

good correlation with their WEOB contents. Meantime, the $R_{a}$ and $R_{q}$ of modified asphalt binder advance as the lightweight components increase, which indicates that the adhesion property has improved.

\section{Conclusion}

In this paper, the influence of WEOB as an additive on SBSmodified asphalt has been studied, including chemical compounds, low- and high-temperature property, and rheology. The mechanism for the influences was analyzed. Based on the above results and discussion, the following conclusions can be drawn:

(1) WEOB is mainly composed of small molecular compounds similar to the asphalt composition, such as cycloalkanes, linear alkanes, various anhydrides, and their derivatives, which favored their physical miscibility between WEOB and asphalt.

(2) Adding WEOB can improve the high-temperature resistance against rutting performance and lowtemperature fatigue cracking resistance of SBSmodified asphalt.

(3) With the increase of WEOB concentration, the contents of colloid gradually increases, which promotes the swelling and compaction of SBS polymer network structure. Furthermore, WEOB promotes the polarity of SBS and forms graft product MAH-g-SBS with asphalt, thus inhibiting the thermal movement of asphalt molecules. On the contrary, light components have a good correlation with the surface roughness of modified asphalt, the results show that the modified asphalt has good rutting resistance.

(4) As a preliminary study, the data in this paper were limited because only one WEOB source was included in evaluating the properties of SBS-modified asphalt. Therefore, a follow-up study should focus on increasing the number of different samples, in addition, it is necessary to investigate the aging resistance of the modified asphalt binders, to verify and evaluate the overall performance of WEOB-modified SBS asphalt.

\section{Data Availability}

All data, models, and code generated or used during the study appear in the submitted article.

\section{Conflicts of Interest}

The authors declare no conflicts of interest. 


\section{Acknowledgments}

This research was funded by the Chengluojian Expressway Project (4th Ring Road to 5th Ring Road section) and Project Department of Chengluojian Expressway Project (4th Ring Road to 5th Ring Road) of China Construction Third Bureau Group Co., Ltd.

\section{References}

[1] V. Pelitli, Ö. Doğan, and H. J. Köroğlu, "Waste oil management: analyses of waste oils from vehicle crankcases and gearboxes," Global Journal of Environmental Science and Management, vol. 3, no. 1, pp. 11-20, 2017.

[2] J. Rincón, P. Cañizares, and M. T. García, "Regeneration of used lubricant oil by ethane extraction," The Journal of Supercritical Fluids, vol. 39, no. 3, pp. 315-322, 2007.

[3] T. You, Y. Shi, L. N. Mohammad, and S. B. Cooper, "Laboratory performance of asphalt mixtures containing Re-refined engine oil bottoms modified asphalt binders," Transportation Research Record: Journal of the Transportation Research Board, vol. 2672, no. 28, pp. 88-95, 2018.

[4] S. B. Cooper, L. N. Mohammad, and M. A. Elseifi, "Laboratory performance of asphalt mixtures containing recycled asphalt shingles and Re-refined engine oil bottoms," Journal of Materials in Civil Engineering, vol. 29, no. 9, Article ID 04017106, 2017.

[5] A. I. Essawy, A. M. M. Saleh, M. T. Zaky, R. K. Farag, and A. A. Ragab, "Environmentally friendly road construction," Egyptian Journal of Petroleum, vol. 22, no. 1, pp. 189-198, 2013.

[6] R. C. Barborak, C. E. Coward, and R. E. Lee, "Detection and estimation of Re-refined engine oil bottoms in asphalt binders: Texas department of transportation's approach with wavelength dispersive X-ray fluorescence spectroscopy," Transportation Research Record: Journal of the Transportation Research Board, vol. 2574, no. 1, pp. 48-56, 2016.

[7] I. A. Qurashi and A. K. Swamy, "Viscoelastic properties of recycled asphalt binder containing waste engine oil," Journal of Cleaner Production, vol. 182, pp. 992-1000, 2018.

[8] S. Liu, A. Peng, J. Wu, and S. B. Zhou, "Waste engine oil influences on chemical and rheological properties of different asphalt binders," Construction and Building Materials, vol. 191, pp. 1210-1220, 2018.

[9] S. Aleer, E. M. Adetutu, T. H. Makadia, S. Patil, and A. S. Ball, "Harnessing the hydrocarbon-degrading potential of contaminated soils for the bioremediation of waste engine oil," Water, Air, and Soil Pollution, vol. 218, no. 1-4, pp. 121-130, 2010.

[10] W. Wang, M. Jia, W. Jiang et al., "High temperature property and modification mechanism of asphalt containing waste engine oil bottom," Construction and Building Materials, vol. 261, 2020.

[11] A. Soleimani, S. Walsh, and S. A. M. Hesp, "Asphalt cement loss tangent as surrogate performance indicator for control of thermal cracking," Transportation Research Record: Journal of the Transportation Research Board, vol. 2126, no. 1, pp. 39-46, 2009.

[12] S. A. M. Hesp and H. F. Shurvell, "X-ray fluorescence detection of waste engine oil residue in asphalt and its effect on cracking in service," International Journal of Pavement Engineering, vol. 11, no. 6, pp. 541-553, 2010.

[13] J. D’Angelo, K. Grzybowski, and S. Lewis, "Canadian technical asphalt, A," in Asphalt Binder Modification with Re-refined
Heavy Vacuum Distillation Oil, pp. 257-275, RHVDO, British Columbia, Canada, 2012.

[14] M. Yu, J. Li, X. Cui, D. Guo, and X. Li, "Antiageing performance evaluation of recycled engine oil bottom used in asphalt rejuvenation," Advances in Materials Science and Engineering, vol. 2019, Article ID 2947170, 8 pages, 2019.

[15] D. J. Mensching, A. Andriescu, C. DeCarlo, X. Li, and J. S. Youtcheff, "Effect of extended aging on asphalt materials containing re-refined engine oil bottoms," Transportation Research Record: Journal of the Transportation Research Board, vol. 2632, no. 1, pp. 60-69, 2017.

[16] X. Li, N. Gibson, A. Andriescu, and T. Arnold, "Performance evaluation of REOB-modified asphalt binders and mixtures," Road Materials and Pavement Design, vol. 18, no. 1, pp. 128-153, 2017.

[17] D. J. Mensching, A. Andriescu, C. DeCarlo, X. Li, and J. S. Youtcheff, "Effect of extended aging on asphalt materials containing Re-refined engine oil bottoms," Transportation Research Record: Journal of the Transportation Research Board, vol. 2632, no. 1, pp. 60-69, 2017.

[18] X. Yang, J. Mills-Beale, and Z. You, "Chemical characterization and oxidative aging of bio-asphalt and its compatibility with petroleum asphalt," Journal of Cleaner Production, vol. 142, pp. 1837-1847, 2017.

[19] M. Paliukaite, M. Assuras, and S. A. M. Hesp, "Effect of recycled engine oil bottoms on the ductile failure properties of straight and polymer-modified asphalt cements," Construction and Building Materials, vol. 126, pp. 190-196, 2016.

[20] S. Liu, S. B. Zhou, and Y. Xu, "Evaluation of cracking properties of SBS-modified binders containing organic montmorillonite," Construction and Building Materials, vol. 175, pp. 196-205, 2018.

[21] 316-13, A. T., Standard Method of Test for Viscosity Determination of Asphalt Binder Using Rotational Viscometer, American Association of State and Highway Transportation Official, Washington, DC, USA, 2013.

[22] R. Zhang, H. Wang, Z. You, X. Jiang, and X. Yang, "Optimization of bio-asphalt using bio-oil and distilled water," Journal of Cleaner Production, vol. 165, pp. 281-289, 2017.

[23] H. Shi, D. Shi, C. Li, S. Luan, J. Yin, and R. K. Y. Li, "Preparation of functionalized graphene/SEBS-g-MAH nanocomposites and improvement of its electrical, mechanical properties," Materials Letters, vol. 133, pp. 200-203, 2014.

[24] A. Zhang Aimin and L. Chao, "Chemical initiation mechanism of maleic anhydride grafted onto styrene-butadienestyrene block copolymer," European Polymer Journal, vol. 39, no. 6, pp. 1291-1295, 2003. 